\title{
Severe Inflammation Indicates High Risk of HSIL: from a Cross-Sectional Study
}

Tengfei Long ${ }^{\# 1}$, Lingli Long ${ }^{\# 2}$, Yaxiao Chen ${ }^{\# 1}$, Yubin $\mathrm{Li}^{3}$, Ying Tuo ${ }^{4}$ Yue $\mathrm{Hu}^{2}$, lingling Xie ${ }^{2}$, Gui He${ }^{5,}$ Wen $\mathrm{Zhao}^{3}$, Xiaofang $\mathrm{Lu}^{*}$, Zhongqiu Lin ${ }^{* 1}$

${ }^{1}$ Department of Gynaecology and Obstetrics, Sun Yat-Sen Memorial Hospital, Sun Yat-Sen University, Guanghzou, China, 510120; longtengfei811@163.com (T.F.L.),

xielingling86@sina.com (L.L.X), lin-zhongqiu@163.com (Z.Q.L), lovelystone0617@163.com (Y.X.C)

${ }^{2}$ Translation Medicine Center, The First Affiliated Hospital, Sun Yat-Sen University, Guangzhou, China, 510080; longll@mail.sysu.edu.cn(L.L.L), huyue29@mail2.sysu.edu.cn (Y.H.)

${ }^{3}$ The Reproductive Center, The First Affiliated Hospital, Sun Yat-Sen University, Guangzhou, China,510080;liyubin97200@163.com (Y.B.L.), zhaow37@mail2.sysu.edu.cn (W.Z)

${ }^{4}$ Department of pathology, The First Affiliated Hospital, Sun Yat-Sen University, Guangzhou,China, 510080; tuoying0902@126.com (T.Y)

${ }^{5}$ Cellular \& Molecular Diagnostics Center, Sun Yat-Sen Memorial Hospital, Sun Yat-Sen University, Guanghzou, China, 510120; hegui36@mail.sysu.edu.cn (H.G)

${ }^{6}$ Department of pathology, The Seventh Affiliated Hospital, Sun Yat-Sen University, Shenzhen, China, 518107; zdluxiaofang2003@163.com (X.F.L.);

\# The authors contributed equally to this work.

* Address correspondence and reprint to: Z.Q. Lin, Department of Gynaecology and Obstetrics, Sun Yat-Sen Memorial Hospital, Sun Yat-Sen University, Guanghzou, China, 510120, China. Tel: 138-0292-1545.

Address correspondence and reprint to: X.F. Lu, Department of pathology, The Seventh Affiliated Hospital, Sun Yat-Sen University, Shenzhen, China, 518107.Tel:+86 13580560209 


\begin{abstract}
Inflammation has been reported as a facilitator in cervical oncogenesis, but the correlation between inflammation and cytology abnormality including Cervical Intraepithelial Neoplasia (CIN) remains uncertain. The aim of this study was to investigate the correlation between them with ThinPrep cytological test (TCT) as a screening tool for cervical cancer and CIN, which can identify abnormal morphology of cervical mucosa epithelium and inflammation degrees. A retrospective analysis of clinical data from 48101 women undergoing TCT in the affiliated hospitals of Sun Yat-Sen University (SYSU) revealed that among the $8.87 \%$ (4102 cases) total positive rate of ASC, LSIL and HSIL, 67.7\% (2777/4102) of TCT positive samples had inflammatory infection. The rate of severe inflammation was significantly higher in cytological abnormality group than the control group $(15.1 \%$ vs. $2 \%, \mathrm{P}=0.000)$. Our results showed that severe inflammation significantly increased incidence of cytological abnormality by 12.59 times and elevated the risk of HSIL by 756.47 times. In conclusion, severe inflammation increased the risk of cytological abnormality, and should be viewed as an important risk of HISL. These results of our study remind clinicians to be more watchful for women with severe cervical inflammation in TCT reports for earlier prevention of the HSIL.
\end{abstract}

Keywords:TCT; cytological abnormality; cervical intraepithelial neoplasia; inflammation; progression

\title{
1. Introduction
}

Cervical cancer is the most common malignancy in women of developing countries and second only to breast cancer worldwide[1], with approximately 530,000 new cases annually, including approximately 102,000 in China in 2014[2, 3$]$. CIN as precursor of cervical cancer describing the appearance of dysplasia of squamous cells on the surface of cervix, has the potentially premalignant transformation ability(Östör, 1993)[4]. Most of CIN I, II subsequently regress to normalcy, but CIN III may potentially develop into cervical carcinoma in situ, and even invasive cervical cancer [ $\underline{5}$, 6].Cervical cancer screenings have been reported successful in controlling the incidence of invasive cervical cancer worldwide [7] for its early detection of CIN, which can lead to early treatment to stop the development of cancer in time.

As a screening tool for cervical cancer and CIN, TCT is a fluid-based, automated technique for collection of exfoliated and aspirated cytological samples [모 $\underline{9}]$. The advanced processes of TCT results in decreased obscuring material, well- preserved cellular morphology, inflammation degrees and minimal cell overlap in the smears $[\underline{10}, \underline{11}]$. The wide utility of TCT has increased the positive rate of 
the cytological diagnosis for cervical diseases, usually CIN [12]. The Bethesda System(TBS) was used to report the results of TCT in clinic [13]. The golden standard--histopathology examination can help to diagnose CIN and cervical cancer in TCT positive samples. In clinical practice, however, doctors often focus on the cytology abnormality in TCT reports while ignore the inflammation degree functions. This rationalizes the suggestions to exclude inflammation degrees from TCT reports, but some studies insisted that inflammation has played an important role in tumorigenesis and progress of cervical cancer [14].

Inflammation has long been implicated as a risk factor for cervical cancer [22].Previous study revealed that women with cervical inflammation were prone to suffer from cervical cancer [15]. The development of epidemiological and molecular biology has demonstrated that most cervical cancer is related to inflammation and infection [16-18]. Human papillomavirus (HPV) is confirmed as the leading cause of cervical cancer by many laboratory studies and epidemiological investigations [19, 20] High risk oncogenic subtypes of HPV with persistent infection result in chronic inflammation, leading to carcinogenesis and causing CIN and cervical cancer[21].Cervical inflammation is a possible risk factor for high-grade lesions in HPV-infected women. Genital infections leading to inflammation is one of the main factors related to cervical cancer in many epidemiological studies. This highlighted the correlation between genital tract inflammation and cervical cancer [22]. The increasing level of inflammation elevated the risk of High-grade lesions by 2 folds, which suggested that cervical inflammation might contribute to the progression of the high-grade lesions [15]. Moreover, laboratory study showed that the elevation levels of inflammatory cytokines IL-6 and IL-8 in cervical epithelial were positively associated with cervical cancer. Thus, evaluation of the inflammation degrees can be helpful for the prediction of cervical cancer.

As the cervical cancer screening tool TCT can detect the cytological abnormality and evaluate the inflammation degrees. However, the correlation between cytology abnormality and inflammation remains uncertain [23]. TCT reports the cytology abnormality but cannot predict whether the patients are at high risk of lesion progression. Thus, it is beneficial to explore a new factor for the prediction of the risk of cytological abnormality progression. In this study, we suggested that TCT was an effective screening tool of CIN, and HISL has a close relationship with CIN3.Therefore, we intended to point out the high risk of HISL. We examined the inflammation degrees in the cytological abnormality slides and revealed the positive correlation between inflammation and different stages of cytological abnormality. In addition, we investigated the risk prediction value of inflammation degrees for HISL by logistic analysis.

\section{Results}

\subsection{Participants characteristics}

During January 2008 and May 2012, 48101women aged 17 76 years old were enrolled for the screening, among whom 5380 cases were TCT positive (including ASC, LSIL, HSIL, AGC and CC). However, our study focused only on the 4102 cases of squamous cell abnormalities (ASC, LSIL and HSIL). We evaluated the clinic characteristics of the 4102 patients. The information included the age distribution, smoking status (never, current), education, age at start of active sex life, number of sexual 
partners, contraceptive methods, and socioeconomic characteristics of the participants as described in Table 1.

Table 1. Distribution of demographic characteristics of study subjects.

\begin{tabular}{|c|c|c|c|c|c|c|c|}
\hline \multirow[t]{2}{*}{ Characteristics } & \multicolumn{2}{|l|}{ ASC } & \multicolumn{2}{|c|}{ LSIL } & \multicolumn{2}{|c|}{ HSIL } & \multirow[b]{2}{*}{ P-value } \\
\hline & $\mathbf{N}$ & $\%$ & $\mathbf{N}$ & $\%$ & $\mathbf{N}$ & $\%$ & \\
\hline \multicolumn{8}{|l|}{ Smoking status } \\
\hline never & 3089 & 91.4 & 553 & 94.6 & 125 & 90.9 & 0.739 \\
\hline current & 291 & 8.6 & 32 & 5.4 & 12 & 9.1 & \\
\hline \multicolumn{8}{|c|}{ Age at enrollment(years) } \\
\hline$\leqq 25$ & 145 & 4.3 & 32 & 5.4 & 0 & 0 & 0.555 \\
\hline$>25$ & 3235 & 95.6 & 553 & 94.6 & 137 & 100 & \\
\hline \multicolumn{8}{|l|}{ education } \\
\hline Primary school & 439 & 13.0 & 52 & 8.9 & 25 & 18.2 & 0.866 \\
\hline Middle school & 1416 & 41.9 & 251 & 42.9 & 56 & 40.9 & \\
\hline undergraduate & 1379 & 40.8 & 240 & 41.1 & 44 & 31.8 & \\
\hline graduate & 145 & 4.3 & 42 & 7.1 & 12 & 9.1 & \\
\hline \multicolumn{8}{|c|}{ Age at sexual debut(years) } \\
\hline$\leqq 20$ & 1055 & 31.2 & 209 & 35.7 & 12 & 54.5 & 0.121 \\
\hline$>20$ & 2325 & 68.8 & 376 & 64.3 & 10 & 45.5 & \\
\hline \multicolumn{8}{|c|}{ Lifetime no. Sexual partners } \\
\hline $1-2$ & 2761 & 81.7 & 460 & 78.6 & 75 & 54.5 & 0.02 \\
\hline$\geqq 3$ & 619 & 18.3 & 125 & 21.4 & 62 & 45.5 & \\
\hline \multicolumn{8}{|c|}{ Contraceptive methods } \\
\hline condom & 1706 & 50.5 & 282 & 48.2 & 75 & 54.5 & 0.372 \\
\hline Contraceptive pills & 74 & 2.2 & 0 & 0 & 0 & 0 & \\
\hline IUD & 545 & 16.1 & 178 & 30.4 & 25 & 18.2 & \\
\hline others & 1055 & 31.2 & 125 & 21.4 & 37 & 27.3 & \\
\hline
\end{tabular}




$\begin{array}{lrrrrrrr}\leqq 5000 & 1453 & 43.0 & 209 & 35.7 & 37 & 27.3 & 0.34 \\ >5000 & 1927 & 57.0 & 376 & 64.3 & 100 & 72.7 & \end{array}$

Values are numbers (percentage) unless otherwise stated

There were no significant differences in the age distribution, smoking status (never, current), education, age at start of active sex life, contraceptive methods, and socioeconomic characteristics. However, the multiple sexual partners predicted the high risk of cytological abnormality $(\mathrm{p}=0.02)$.

\subsection{Qualitative analysis of TCT screening}

We evaluated the quality of 48,101 cervical cytological slides of ThinPrep Cytology Test (TCT). $96.16 \%$ (46255/48101) of the slides fulfilled the requirement of TCT. $3.84 \%(1846 / 48101)$ of the slides were scored as unsatisfied samples due to the poor quality (Table 2). Our study was based only on the 46255 cases of the satisfied and general slides to minimize the misdiagnosis rate.

Table 2. Distribution of cervical cytology slides in different satisfaction degrees.

\begin{tabular}{lcc}
\hline Satisfaction Degree & Number & Percentage (\%) \\
\hline Satisfied & 36420 & 75.71 \\
General & 9835 & 20.45 \\
Unsatisfied & 1846 & 3.84 \\
\hline
\end{tabular}

The purpose of Table 3 is to show the faults and issues of the 11681 general and unsatisfactory slides. Obviously, excessive impurities in the slides were the most major cause, and other issues included thick smears, excessive blood cells or none cervical cells in the slides.

Table 3. Problems of 11681 slides

\begin{tabular}{lll}
\hline Problems of slides & Number & Percentage (\%) \\
\hline None cervical cells & 676 & 1.41 \\
Excessive blood cells & 3002 & 6.24 \\
Very thick smear & 3145 & 6.54 \\
Excessive impurities & 4858 & 10.10 \\
\hline
\end{tabular}

2.3 Correlation between histopathological findings and TCT

TCT results were classified by the 2014 TBS, a system for reporting cervical or vaginal cytological diagnoses (table 4). In the 46255 cytological cases, 40875 (88.37\%) samples were reported negative, and only 4102 cases were reported as cytological abnormality (ASC, LSIL, HSIL) by TCT, accounting for $8.87 \%$ of total samples. Among the 46255 participants of our study, there were 3380 , 585 and 137 cases identified as positive for ASC, LSIL, and HSIL, accounting for $7.31 \%, 1.21 \%$, and 
$0.28 \%$, respectively.

We used colposcopy examination and histopathological biopsy to diagnose CIN in the 4102 TCT positive samples. It showed that 2965 (72.28\%) women had CIN including CIN1, CIN2 and CIN3 and cervical cancer, $2355(57.41 \%), 359(8.75 \%), 295(7.19 \%)$ and $7(0.17 \%)$ cases of cytological abnormality were CIN1, 2, 3 and cervical cancer, respectively.

As the results shown in Table 4, 82.4\% (3318/4102) of the cytological abnormality were identified as ASC by TCT and $62.81 \%$ of ASC were CIN1 determined by histopathology. But only $1.36 \%$ of ASC was CIN3. It indicated that most of ASC patients were the low grade lesion at the early stage of neoplasia. However, the pathological diagnosis of patients with LSIL may have multiple possibilities. The probability of CIN1, 2 and 3 were $37.78 \%, 28.38 \%$ and $29.40 \%$ respectively. As to HSIL, $56.20 \%$ of HSIL patients had CIN3, even cervical cancer (2.92\%). Based on the above results, we could find that ASC indicated a high probability of CIN1, and HSIL indicated a high probability of CIN3. But LSIL had more uncertain possibilities of CIN.

Our results showed a clear relationship between cytological abnormality and the progression of CIN. Among the 4102 TCT positive samples, the rates of CIN were $68.79 \%, 95.21 \%$, and $95.62 \%$ in ASC, LSIL and HSIL group, respectively (Table 4). The percentages of CIN3 in ASC, LSIL and HSIL groups were $1.36 \%, 29.40 \%$ and $56.20 \%$ respectively. The percentage of CIN3 was the highest in HSIL group. As the severity of cervical cytology abnormalities increased, the proportion of CIN3 also gradually increased. Interestingly, these distributions of CIN in ASC, LSIL and HSIL suggested that HSIL patients should be more watchful for CIN3 and cervical cancer.

Table 4. Correlation between histopathological findings and TCT

\begin{tabular}{|c|c|c|c|c|c|}
\hline \multirow[b]{2}{*}{ histopathology } & & \multicolumn{4}{|l|}{ TCT positive } \\
\hline & & ASC (N/\%) & LSIL (N/\%) & HSIL (N/\%) & Total (N/\%) \\
\hline \multirow[t]{3}{*}{ negative } & & $1055(31.21)$ & $25(4.27)$ & $6(4.38)$ & $1086(26.47)$ \\
\hline & CIN1 & $2123(62.81)$ & $221(37.78)$ & $11(8.03)$ & $2355(57.41)$ \\
\hline & CIN2 & $154(4.56)$ & $166(28.38)$ & $39(28.47)$ & $359(8.75)$ \\
\hline \multicolumn{6}{|l|}{ positive } \\
\hline & CIN3 & $46(1.36)$ & $172(29.40)$ & $77(56.20)$ & $295(7.19)$ \\
\hline & $\mathrm{CC}$ & $2(0.06)$ & $1(0.17)$ & $4(2.92)$ & $7(0.17)$ \\
\hline & total & $3380(82.40)$ & $585(14.26)$ & $137(3.34)$ & 4102 \\
\hline
\end{tabular}

2.4 The correlation between cervical inflammation degrees and cytological abnormality

To investigate the influence of inflammation degree on cytological abnormality, 4102 slides of TCT positive samples were collected for inflammation evaluation. The control group was TCT negative samples. We found that $69.87 \%$ (2866/4102) of the TCT positive samples had cervical inflammation. 
It showed that $50.52 \%, 14.75 \%$ and $15.10 \%$ of the cytological abnormality samples had mild, moderate and severe inflammation, respectively. In the control group, $42.5 \%, 15.8 \%$ and $2 \%$ of the samples had mild, moderate and severe inflammation. There were no significant difference in mild and moderate inflammation rates between cytological abnormality group and the control group $(\mathrm{P}>0.05)$. However, the rate of the severe inflammation was significantly higher in the cytological abnormality group $(15.1 \%)$ than in the control group $(2 \%),(\mathrm{P}<0.05)$. These results indicated that the severe inflammation had a positive relationship with cytological abnormality (Figure 5-a). In order to explore the influence of different degrees of inflammation in the ASC, LSIL and HSIL, we analyzed the percentage of mild inflammation, moderate inflammation and severe inflammation in control group, ASC group, LSIL group and HSIL group. The result indicated that in the control group and the ASC group, the percentages of severe inflammation $(2 \%, 19.46 \%)$ were lower than those with mild $(42.5 \%$, $43.8 \%$ ) and moderate inflammation $(15.8 \%, 25.58 \%)$. While, in the LSIL and HSIL groups, the percentages of severe inflammation $(43.35 \%, 50.22 \%)$ were higher than mild $(20.80 \%, 13.68 \%)$ and moderate inflammation $(24.52 \%, 26.79 \%)$. Thus, the inflammation severity was positively correlated with the progress of cytological abnormality, and HSIL group had the highest percentage of severe inflammation (Figure 5-b).

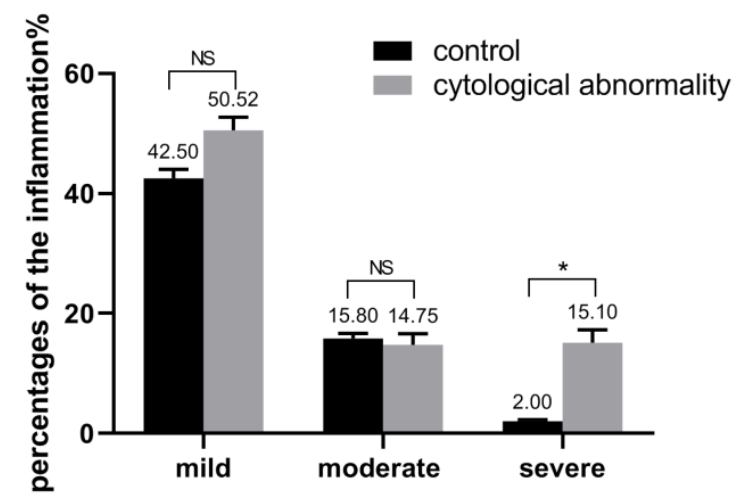

(a)

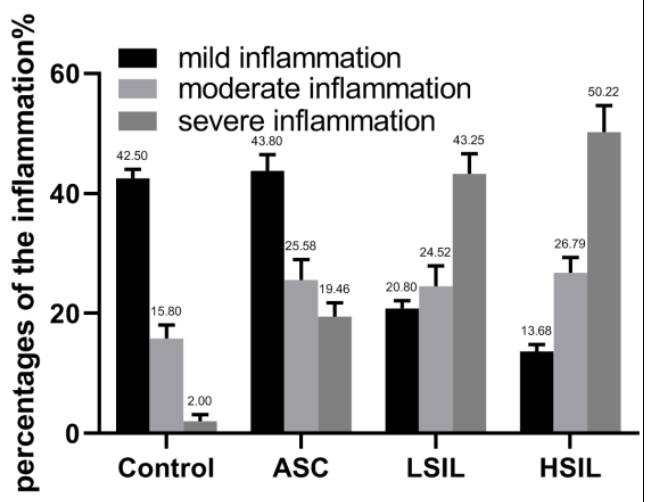

(b)

Figure 5. (a). The percentages of different inflammation degrees in the control and in the cytological abnormality groups; (b). The distribution of different inflammation degrees in each cytological abnormality group compared with the control group.

2.5 Logistic analysis of the relationship between the inflammation degrees and incidence of cytological abnormality

In order to clearly understand the exact risk of inflammation on cytological abnormality, we used logistic regression model to analysis the relationship between the degrees of inflammation and incidence of cytological abnormality. The logistic regression model showed that all degrees of inflammation could enhance the prevalence of cytological abnormality. For severe inflammation particularly, the incidence of cytological abnormality was increased by 12.598 times, while mild and moderate inflammation could only increase the incidence of cytological abnormality by 2.14 and 1.382 times, (Table 5). As the results indicated, severe inflammation was closely related to CIN. 
Table 5. the increased risk of the incidence of cytological abnormality by degrees of inflammation.

\begin{tabular}{llll}
\hline Inflammation & Point & $\mathbf{9 5 \%}$ & Wald \\
degree & estimate & Confidence & limits \\
\hline mild & 2.140 & 1.970 & 2.325 \\
moderate & 1.382 & 1.243 & 1.536 \\
severe & 12.598 & 10.861 & 14.614 \\
\hline
\end{tabular}

2.6 Risk prediction of cytological abnormality progression by different degrees of inflammation

As mentioned above, severe inflammation had higher risk of the cytological abnormality.

It's very important to calculate the odds ratio between different grades of cytological abnormality and different degrees of inflammation. We found that all degrees of cervical inflammation increased the risk of all grades of cytological abnormality. It seemed that the inflammation was positively related to the incidence of cytological abnormality. Obviously, it showed that severe inflammation had the highest risk for HSIL (756.472 times for HSIL). Conspicuously, severe inflammation increased the risk of HISL by 756 times, compared with that in control group (Table 6).

Table 6 Cytological abnormality odds ratio estimates by inflammation degrees

\begin{tabular}{llll}
\hline Inflammation degree & \multicolumn{1}{l}{ ASC } & LSIL & HSIL \\
\hline mild & $2.012(1.846,2.194)^{*}$ & $2.980(2.338,3.798)^{*}$ & $6.719(1.934,23.338)^{*}$ \\
moderate & $1.455(1.298,1.630)^{*}$ & $2.374(1.762,3.198)^{*}$ & $22.421(6.742,74.561)^{* * *}$ \\
severe & $7.094(5.999,8.390)^{* * *}$ & $47.949(36.779, \quad 62.512)^{*}$ & $756.472(239.065,+\infty)^{*}$ \\
\hline
\end{tabular}

“***” $\mathrm{p}>0.05 ; “ * * " \mathrm{p}<0.05$

\section{Discussion}

This cross-sectional study which included 46255 cases of TCT reports and 4102 cases with ASC, LSIL and HSIL aimed to determine the correlation between the inflammatory degrees and cytology abnormality risk. We observed that multiple sexual partners predicted the high risk of cytological abnormality. Moreover, the distribution of the cytology abnormality was in line with CIN. And the increasing inflammation degrees, as indicative of severer inflammation condition of cervical epithelial cells, were positively correlated with increased risk of cytology abnormality. Particularly, women with severe inflammation were at highest risk of cytology abnormality. Patients with HSIL showed a strong 
possibility of CIN3 and the high risk by the presence of severe inflammation. Thus, the results confirmed the study hypothesis that severe inflammation is correlated with the increased risk of HSIL.

In this study, we have described the demographic characteristics of the participants with ASC, LSIL, and HSIL, and we found that multiple sexual partners predicted the high risk of cytological abnormality. Similarly, numerous epidemiology studies showed multiple sexual partners is one of the significant risk factors for developing HSIL [24, 25]. Some studies found that the sexual behavior of women, multiple sexual partners and increasing number of the sexual partners were associated with high-risk HPV (hrHPV) infection [24, 26-28]. However, other studies suggested that with or without HPV infection, having multiple sexual partners is an independent risk factor of cervical cancer [29]. Cervical cancer is a multi-step disease with several contributing co-factors including multiple sexual partners, a compromised immune system and cervical inflammation caused by genital infections, and multiple sexual partners might be related with the infections and inflammation, which could lead to the development of cervical cytological abnormality [30].

TCT is the most advanced cytological examination technique for cervical cancer globally, but the sample quality with the degree of satisfaction is the guarantee of high credibility of TCT results. In our study, the satisfaction rate of TCT was high up to $96.16 \%$ (46255/48101). According to the analysis of the problems of the unsatisfactory slides, it's necessary to standardize operational details: a) collect enough epithelial cells for observation with cotton swabs; b) wipe the secretion after rub-up to brush into the cervix; c) use the voyeuristic for fully exposed cervix; d) contact sufficiently the surface of cervical squamous epithelium and transition zone with cervical cells brush for 8-10 circles at the same direction [31]. It's recommended that sampling is performed by skilled and experienced gynecologists.

Our data showed that the distribution of cytology abnormality was in line with CIN. Previous studies have reported that the TCT positive rate ranged 3.17\%-41.7\% [ $\underline{32}-\underline{35}$ ]. In our study, TCT had a positive rate of $8.87 \%$ (4102/46255), with a high screening sensitivity of 72.28 \%( 2965/4102) of CIN which was diagnosed by histopathological examination. As the severity of cervical cytology abnormalities increased, the proportion of CIN also gradually increased. The results showed that TCT had a high specificity for cytology abnormalities, especially LSIL and HSIL. Once TCT indicated HSIL, doctors should be alert to the high possibility of CIN3 and conduct colposcopy biopsy for the patients in time to confirm the diagnosis. After diagnosed by histopathology, our study found that there was a clear relationship between cytological abnormality and the progression of CIN. ASC was mostly CIN1 (62.81\%), LSIL was mostly CIN2 or CIN3 (57.78\% in total), and HSIL was mostly CIN3 (56.20\%).Some studies have similar rules, but the sample size varies greatly, which affects the persuasiveness of the results [35-37]. According to our study with a huge sample population, the results of TCT can show more information and clues at clinic. Clinically, CIN3 must be treated to prevent the development of cervical cancer or even invasive cervical cancer. CIN2 should be judged by combining the results of HPV DNA testing and immunohistochemical of P16. Most CIN1 can be evolving into chronic inflammation without treatment. With the positive TCT reports, gynecologists would know the possible histopathology results for patients, because TCT was often in line with CIN. And that's why most of the gynecologists would like to use TCT as primary screening tool world widely [38-40]. 
TCT is capable of identifying patients with cytology abnormality and inflammation, and it can determine if these patients are at a high risk of cytology abnormality. Previous studies found that inflammation as an initiation and carcinogenesis factor is positively correlated to the cervical cancer [31]. Our results revealed that, mild and moderate inflammation had no significant difference between cytological abnormality and control $(\mathrm{P}>0.05)$, while the incidence of severe inflammation was significantly higher in cytological abnormality than in the control $(\mathrm{P}<0.05)$ (Figure $5 \mathrm{~A})$. It showed that mild and moderate inflammation didn't increase the risk of cytology abnormality significantly. However, severe inflammation is more dangerous than mild and moderate inflammation. The rates of severe inflammation were in line with the development of cytological abnormality (Figure 5B). And severe inflammation increased the risk of HISL by 756 times higher than that in control group. Therefore, severe inflammation can be viewed as a high risk factor for cytological abnormality, even CIN3. Severe inflammation was possibly the high risk factor of cytological abnormality, which is in line with results from previous studies $[\underline{15}, \underline{41}]$. As our data shown in table 4, more than half of HSIL was CIN3 diagnosed by histopathology examination. Thus, patients with severe inflammation are more likely to progress to CIN3. Therefore, inflammation as an alternative factor can be required to serve as supplementary method for indication of CIN3. So emphasizing the evaluation of the inflammation degree in TCT reports is necessary. Inflammatory conditions can lead to pre-neoplastic manifestations in the cervical epithelium. And severe inflammation may serve as a new marker for early detection of CIN. Women with severe inflammation should be paid more attentions to for prevention of the cytological abnormality.

Although this study is one of the few studies focusing on inflammation associated cytological abnormalities risk, and several other studies on the association between inflammation and CIN, which lead to cervical cancer, revealed similar results. A case-control study in the Costa Rican natural history study of inflammation and cervical neoplasia reported that cervical inflammation may be correlated with high grade lesions. Moreover, it was suggested that cervical inflammation may be a cofactor for high-grade cervical lesions in women infected with oncogenic HPV [15]. Similarly, two studies reported that genital infections leading to chronic inflammation increased the risk of developing CIN [42, 43]. In all these studies, it was evident that inflammation was strongly related with CIN, a precursor lesion for development of cervical cancer. In another study, high rates of cervical cancer existed with unusually high levels of unexplained cervical inflammation [15]. Furthermore, it was reported that the higher degree of cervical inflammation in population were ecologically associated with higher incidence of cervical neoplasia including CIN [15]. And in other cancers, chronic inflammation exposes the tissue to constant genotoxic damages. In cervical cancer, chronic inflammation promotes the initial changes in CIN caused by hrHPV and contributes to viral persistence and disease progression [44].

Furthermore, extensive studies have demonstrated that inflammation of cervical mucosa predisposes the epithelium to carcinogenesis. They mainly focused on the immune inhibited, co-infection, persistent infection and tumorigenesis [45-52]. However, the fundamental mechanisms of inflammation promoting the cervical carcinogenesis are still unclear. Our results also indicate that the inflammation may serve an important role in carcinogenesis. Inflammation is a nonspecific biological 
response of vascular tissue caused by exogenous factors, like pathogenic microbial infection [53]. It can activate healing process and eliminate the injurious stimuli, which is considered as a mechanism of innate immunity [54]. Inflammation caused by genital infection can produce nonspecific protective antimicrobial oxidants which can also contribute to oxidative damage to host DNA, resulting in cancer [55].Inflammation related factors, like IL6, is an important factor promoting the progression of the disease and the development of tumors [56]. Many studies supported that inflammation is possibly a risk factor for carcinogenesis [15].Our study clearly showed a positive relationship between inflammation and HSIL, and 56.2\% of HISL patients had CIN3. Furthermore, serve inflammation can increase HSIL by 756 times. Therefore, we suggest that TCT reports should show the degree of the inflammation, because it is an important factor for the progression of cervical cancer.

\section{Materials and Methods}

\subsection{Subject Recruitment}

Participants of the study were recruited from women with history of sexual life visiting the Obstetrics-Gynecology clinics of the SYSU Affiliated Hospitals between January 2008 and May 2012.We obtained the written informed consents from all participants after careful face-to-face explanation of the purpose and implications of our findings. The study was registered under the number (\#350) and approved by the Institutional Review Board in Sun Yat-Sen Memorial Hospital. (Fig. 1). All participating women were informed and asked to complete a consent form before the study started, and similar explanation was conducted again and approved by the participants before the experienced gynecologist collected the Pap smear with TCT for each participant.

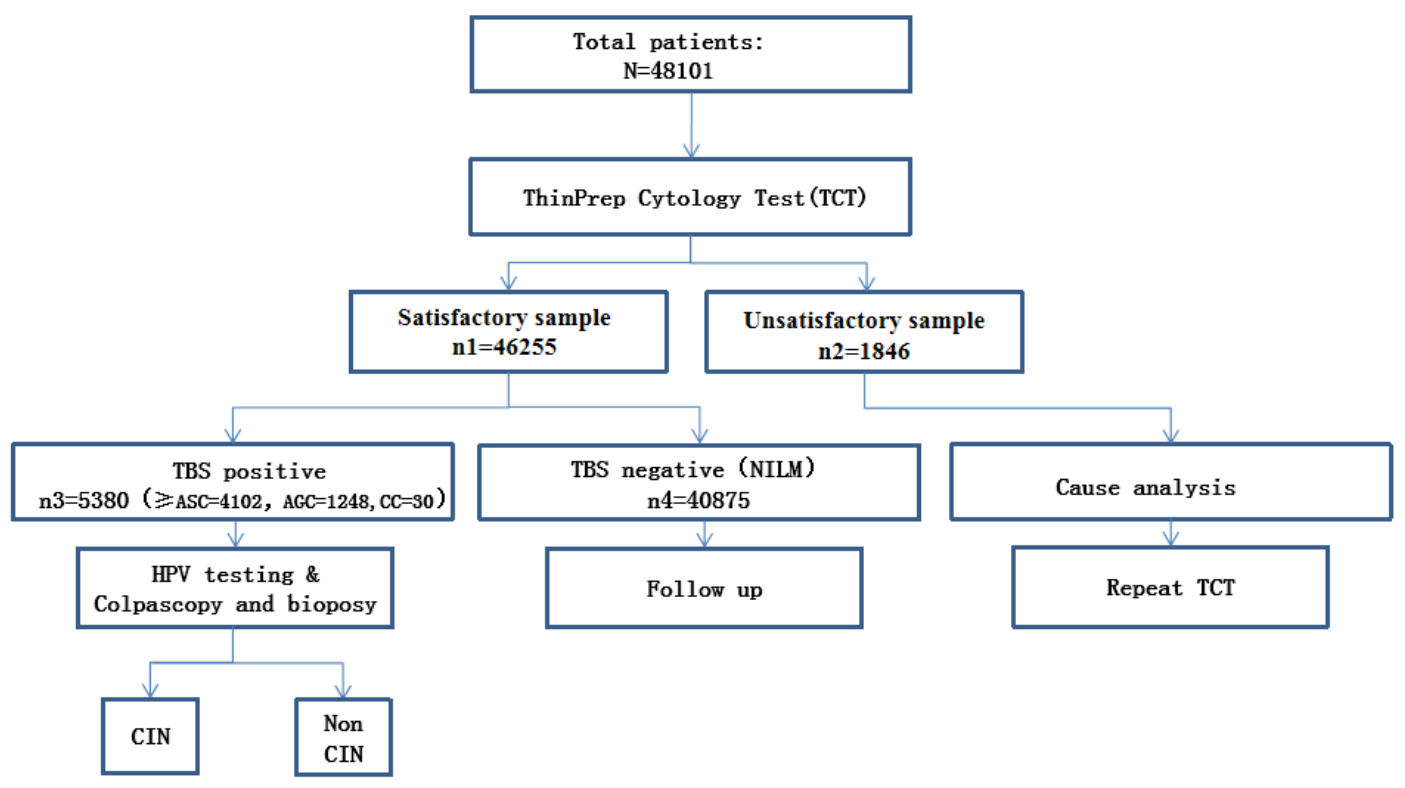

Figure 1. Flow chart of the patient recruitment.

TCT=ThinPrep Cytology Test; ASC=Atypical squamous cells; AGC=Atypical glandular cells of undetermined significance; $\mathrm{CC}=$ cervical cancer; NILM=Negative results are negative for Intraepithelial lesion or malignancy; $\mathrm{CIN}=$ cervical intraepithelial neoplasia. 


\subsection{ThinPrep Cytology Test (TCT) and diagnostic criteria}

We used TCT as the cervical cytology method. And we followed the thin layers of liquid cell technology application principle: a) prepared the special plastic scraper and neck pipe brush; b) gathered exfoliated cells at the site of cervical squamous-columnar junction; c) preserved the cells collected in a special bottle with cell preserving fluid; d) detached the blood cells and mucus cells; e) kept the epithelial cells and inflammatory cells; f) turned them into thin layer after filtering; g) inspected microscope slides.

\subsubsection{Preparation of ThinPrep slides}

Collected cervical exfoliatedcells of the 48101 women were stored in liquid preservative to prepare ThinPrep slides and stained by Pap staining. The samples were transferred to tubes and then we added $4 \mathrm{~mL}$ stratified fluid (CytoRichDeagent Reagent) into each tube. Tubes containing samples were centrifuged with $1080 \mathrm{r} / \mathrm{min}$ for $2 \mathrm{~min}$. After that, the supernatant was removed, and samples were centrifuged with 2010r/min for 10min, followed by quickly discarding supernatant. Each tube was dried carefully by using paper to absorb water and then tubes were swirled for $15 \pm 5$ s. Finally all tubes were placed on the AutoCyte PREP for staining.

\subsubsection{Observers}

Those who read ThinPrep Pap slides were pathologists of the SYSU affiliated hospitals. All of them had above 3 years working experience in reading cervical ThinPrep Pap slides by then.

\subsubsection{TCT samples satisfactory standard}

An adequate liquid-based preparation (LBP) from a woman should have an estimated minimum of at least 5,000 well-visualized/well-preserved cervical squamousor squamous metaplastic cells. This range applies only to squamous cells. Endocervical cells and completely obscured cells should be excluded from the estimate. A satisfaction scale was used to classify all slides into three levels: satisfied, general and unsatisfied; depending on their quantitation of epithelial cells, glandular epithelial cells, and neutrophile granulocytes.

\subsubsection{Cytological diagnostic criteria}

All samples were stained using standard Pap stain, screened by a cytotechnologist and reported by a cytopathologist based on TBS (the Bethesda system) 2014 criteria. They are : Negative results are negative for Intraepithelial lesion or malignancy (NILM); Positive results are atypical squamous cells of undetermined significance (ASC-US), atypical glandular cells of undetermined significance (AGC), atypical squamous cells-cannot exclude HSIL (ASC-H), low-grade squamous intraepithelial lesions (LSIL), high-grade squamous intraepithelial lesions (HSIL), and squamous cell and glandular cell carcinoma (CC). And the epithelial cells include squamous cells and glandular cells. TCT results in ASC-US below (including the normal and inflammatory cells) are defined as the cytology-negative; ASC-US and above ( $\geqslant$ ASC, including the squamous cell abnormalities which are ASC-US, ASC-H, LSIL, HSIL, SCC, and glandular cell abnormalities which are AGC, and GCC) are defined as the cytology-positive. In our study, we analyzed the squamous cell abnormalities (ASC, LSIL and HSIL). 

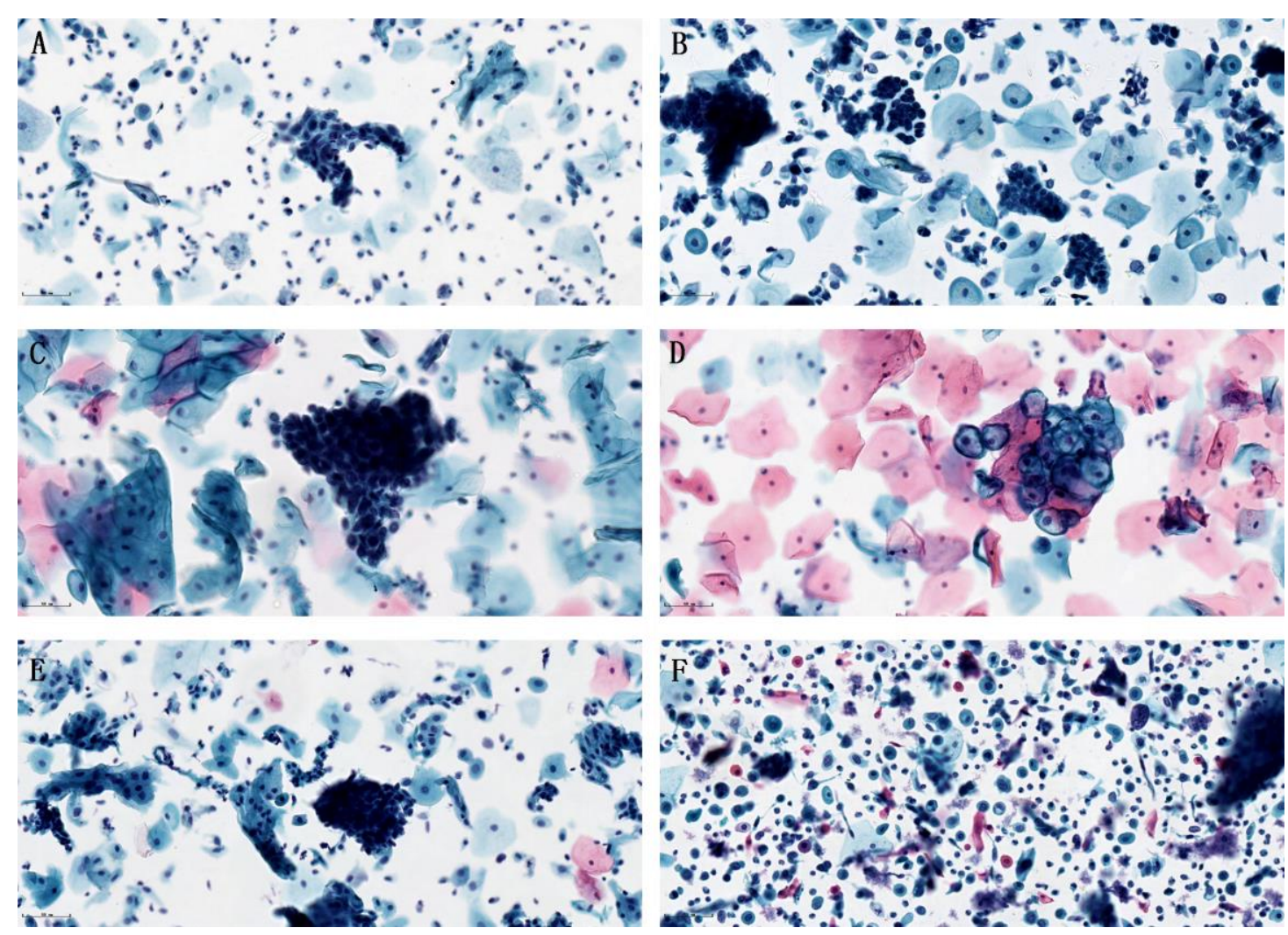

Figure2. TCT slides with Pap staining under microscope. A. Atypical squamous cells of undetermined significance (ASC-US); B. Atypical glandular cells of undetermined significance (AGC); C. Atypical squamous cells-cannot exclude HSIL (ASC-H); ASC referred as ASC-US+ASC-H; D. Low-grade squamous intraepithelial lesions (LSIL); E. High-grade squamous intraepithelial lesions (HSIL); F. Squamous cell carcinoma (CC).

\subsection{Evaluation of Cervical Inflammation}

Cervical inflammation degree depended on the number of neutrophils observed in microscope fields on ThinPrep slides from each study subject. Inflammation degree was classified into three levels: low (5-15neutrophils/field), moderated (16-30 neutrophils/field) and severe $\quad(>30$ neutrophils/field)(Figure 3) . 

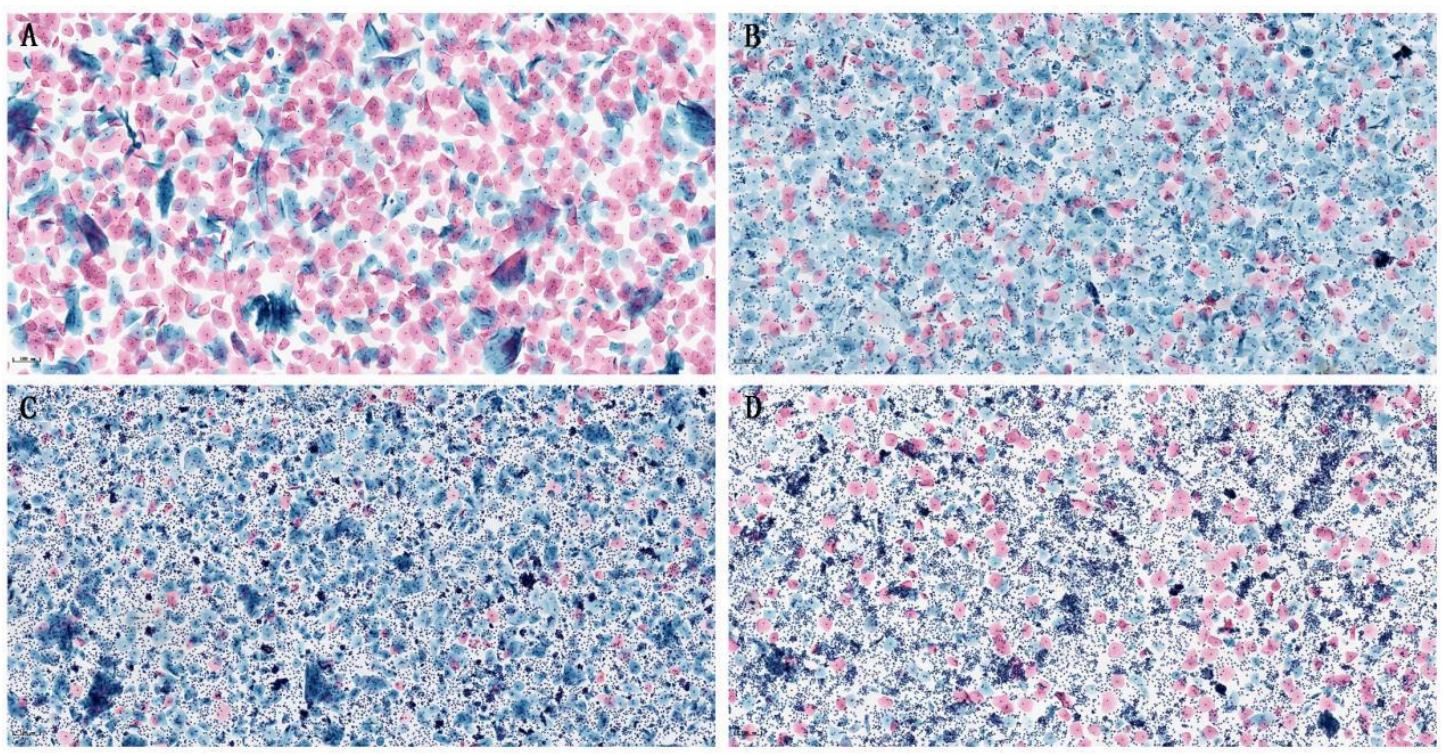

Figure 3. Proportions of control and TCT positive samples with different inflammation degrees. A. no

inflammation in TCT samples; B. mild inflammation in TCT samples; C. moderate inflammation in TCT samples; D. severe inflammation, in TCT samples.

\subsection{Histopathological examination.}

Patients with positive TCT were arranged for colposcopy biopsy and histopathological examination. After the cervix was assessed with 5\% acetic acid application, each distinct area of aceto-white cervical epithelium in the transformation zone was sampled as a lesion-directed biopsy using sharp biopsy forceps. Biopsy would be performed at 4 points (3, 6, 9, and 12 o 'clock) for the normal-appearing cervical epithelium. A single random biopsy in any quadrant of the cervix was added if fewer than four lesion-directed biopsies were taken. Cervical specimens were placed into separate labeled containers with $10 \%$ buffered formalin. Each biopsy was ranked by the severity of colposcopic impression at the time of examination, stained with hematoxylin and eosin, and double-blind diagnosis was performed by two experienced and trained associate directors of pathology and doctors with professional titles.

CIN pathological diagnostic criteria are as following: A) for CIN1: pleomorphic cells involved subsquamous $1 / 3$ of epithelium or less, and most of them are less pleomorphic. Sometimes the cytopathologic changes of HPV infection were observed; B) for CIN2: the heteromorphic cells are involved in the $1 / 2$ or $2 / 3$ of the subsquamous epithelium. A few heteromorphic cells diffuse into the squamous cell line. The epithelium is still well-differentiated, although about a third of the cells are supraecal; C) for CIN3/carcinoma in situ: the upper or entire layer of the squamous epithelium is replaced by heterotropic cells, but the epithelial basement membrane remains clear and intact. When the entire layer is filled with pleomorphic malignant cells, it is classified as carcinoma in situ. 

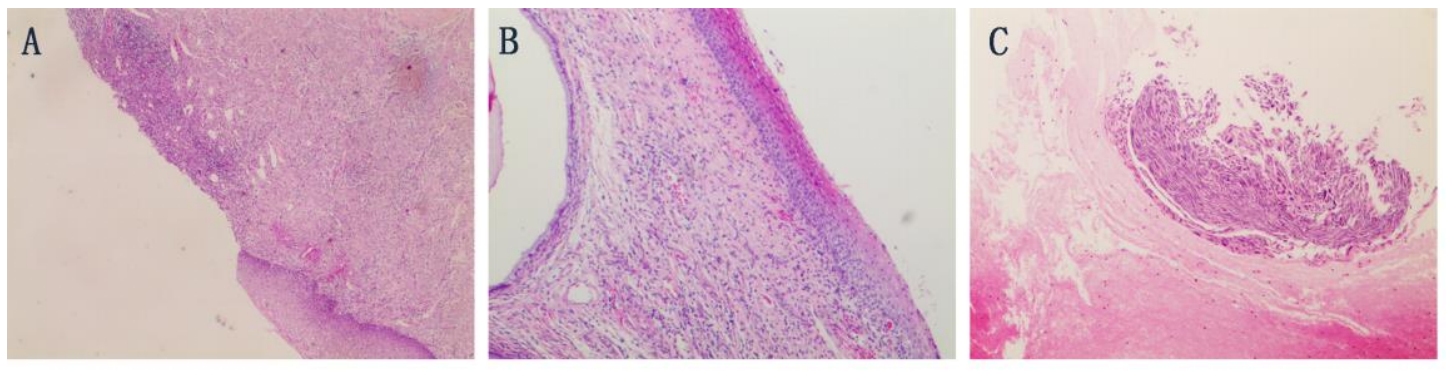

Figure 4 HE staining for (A) CIN1, (B) CIN2, and (C) CIN3.bar=100 $\mu \mathrm{m}$.

\subsection{Statistical Analysis}

The statistical software SPSS 19.0 was used to compare cervical pathogenic microbial and cervical inflammation in cytology positive groups and control. The chi-square test was used for statistical analysis with the significance level set at less than 0.05 .The odds ratio (OR), 95\% confidence intervals $(95 \% \mathrm{CI})$ and $\mathrm{p}$-values from logistic regression were reported as a measure of association. All reported p-values were 2-sided with a significance level of 0.05 .

\section{Conclusions}

In conclusion, TCT, which is widely used in clinical practice, is an effective screening tool for cervical cancer with high diagnostic sensitivity. Our investigation indicated that $72.28 \%$ of TCT positive women had cervical intraepithelial neoplasia (CIN1, CIN2 and CIN3). Our study also showed a clear distribution of CIN1, CIN2 and CIN3 in line with cytological abnormality (ASC, ISIL, and HSIL) based on a huge number of samples. These results highlighted the relationship between cytological abnormality and CIN, helping doctors find out high risk patients of CIN3 by TCT with HSIL and severe inflammation.

Severe inflammation increased the risk of HISL by 756 times, much higher than that in control group. Therefore, severe inflammation can be viewed as a high risk factor for HSIL, even CIN3. So evaluation of the inflammation degree in TCT reports is necessary. It is possible that severe inflammation may serve as a new marker for early detection of CIN3 by TCT. According to our study, doctors can capture more information and clues from a TCT report, if it shows both cytological information and inflammatory information in the report.

\section{Supplementary Materials: no.}

Author Contributions: All of the authors contributed significantly to this work. Tengfei Long and Lingli Long designed the research study and write the article; Yaxiao Chen, Ying Tuo, Yue Hu, Lingling Xie and Gui He collected and analyzed data ; Yubin Li: Carry out literature search, data acquisition and manuscript editing.

Xiaofang Lu and Zhongqiu Lin performed manuscript review and supplied funding support. All authors read and approved the final manuscript.

Funding: The present study was financially supported by grants (81572575) from the National Natural Science Foundation of China Grant.

Acknowledgments: Data for this study were obtained from three university hospitals in Guangzhou, China. We are grateful to each of the staff involved in this study and sincerely appreciate the participants who gave their 
informed consents to our use of their medical records and questionnaires.

Conflicts of Interest: The authors declare no conflicts of interest.

\section{References}

1. Parkin, D.M.; Bray, F.; Ferlay, J.; Pisani, P. Global cancer statistics, 2002. CA Cancer J. Clin. 2005, 55, 74-108.[ https://onlinelibrary.wiley.com/doi/pdf/10.3322/canjclin.55.2.74][ https://www.ncbi.nlm.nih.gov/pubmed /15761078]

2. Lian, L.J. Lin Qiaozhi Gynecology Oncology, 4th ed.;. People's Medical Publishing House.Beijing, China,2006; pp. 312-314

3. Peng, J.R.,Tao S.Y., Wen Y.,Yang X.,Ma J.Q.,Zhao F.,Chen Z.Y.,Zhang G.T.,Qiao Y.L.,Zhao F.H., Yang C.X.. Cost-effectiveness analysis of cervical cancer screening strategies in urban China. Chin J Oncol. 2019,41,

154-160.[ http://zhzlzz.yiigle.com/CN112152201902/1119307.htm?locale=zh_CN][ https://www.ncbi.nlm.nih.gov /pubmed/30862148]

4. Östör, A. G. Natural history of cervical intraepithelial neoplasia: a critical review. Int J. Gynecol Pathol. 1993,12,186 -92.[ https://www.ncbi.nlm.nih.gov/pubmed/8463044]

5. Morris, M.; Roett, MA. Genital cancers in women: cervical cancer. FP Essent. 2015, 438, 18-23.

[https://scholar.google.com/scholar_lookup?journal=FP+Essent.\&title=Genital+cancers+in+women:+cervical+can cer\&author=E+Morris\&author=MA+Roett\&volume=438\&publication_year=2015\&pages=18-23\&pmid=2656904 7\&] [ https://www.ncbi.nlm.nih.gov/pubmed/26569047]

6. Luo, Y. L.;Ye, P.; Zhang, Q. H.; Hu, T. T.; Luo, M. H.; Li, M. Q.;Chen, Q. Methylenetetrahydrofolate reductase C677T polymorphism and susceptibility to cervical cancer and cervical intraepithelial neoplasia: a meta-analysis. PloS one 2012, 7(9), e46272.

[https://journals.plos.org/plosone/article?id=10.1371/journal.pone.0046272][https://www.ncbi.nlm.nih.gov/pubme $\mathrm{d} / 23029458]$

7. Yang, L.; Huangpu, X.M.; Zhang, S.W.;Lu ,F.Z.; Sun, X.D.; Sun, J;Mu, R.; Li, L.D.; Qiao, Y.L. Changes of mortality rate for cervical cancer during 1970's and 1990's periods in China. Acta Academiae Medicinae Sinicae 2003,25, 386-390

[https://www.ncbi.nlm.nih.gov/pubmed/?term=Changes+of+mortality+rate+for+cervical+cancer+during+1970\%2 $7 \mathrm{~s}+$ and $+1990 \% 27 \mathrm{~s}+$ periods+in+China]

8. Papillo, J. L.; Zarka, M. A.; St John, T. L. Evaluation of the ThinPrep Pap test in clinical practice. Acta cytological 1998, 42, 203-208.

[https://www.karger.com/Article/Abstract/331547][https://www.ncbi.nlm.nih.gov/pubmed/9479341]

9. Guidos, B. J.; Selvaggi, S. M. Use of the Thin Prep ${ }^{\circledR}$ Pap Test ${ }^{\mathrm{TM}}$ in clinical practice. Diagnostic cytopathology 20, 70-73. [https://www.ncbi.nlm.nih.gov/pubmed/?term=Use+of+the+Thin+Prep+Pap+Test+in+clinical+practice]

10. Hutchinson, M.; Agarwal, P.; Denault, T.; Berger, B.; Cibas, E. A new look at cervical cytology. ThinPrep multicenter trial results. Acta cytological 1992, 36, 499.

[https://www.ncbi.nlm.nih.gov/pubmed/?term=A+new+look+at+cervical+cytology.+ThinPrep+multicenter+trial+r esults]

11. Arbyn, M.; Bergeron, C.; Klinkhamer, P.; Martin-Hirsch, P.; Siebers, A. G.; Bulten, J. Liquid compared with conventional cervical cytology: a systematic review and meta-analysis. Obstetrics \& Gynecology 2008, 111, 167-177. [https://www.ncbi.nlm.nih.gov/pubmed/18165406]

12. Abulafia, O.; Pezzullo, J. C.; Sherer, D. M. Performance of ThinPrep liquid-based cervical cytology in comparison with conventionally prepared Papanicolaou smears: a quantitative survey. Gynecologic oncology 2003, 90, 137-144.

[https://www.gynecologiconcology-online.net/article/S0090-8258(03)00176-8/fulltext][https://www.ncbi.nlm.nih. gov/pubmed/?term=Performance+of+ThinPrep+liquid-based+cervical+cytology+in+comparison+with+convention ally+prepared+Papanicolaou+smears $\% 3 \mathrm{~A}+\mathrm{a}+$ quantitative+survey]

13. Guang-ming, W. TCT value of detection. Harbin Medical Journal 2010, 4, 049.

14. Luo,Y.L.; Ye,P.;, Zhang,Q.H.; Hu,T.T.; Luo,M.H.; Li,M.Q.; Chen,Q.Methylenetetrahydrofolate reductase $\mathrm{C} 677 \mathrm{~T}$ polymorphism and susceptibility to cervical cancer and cervical intraepithelial neoplasia: a meta-analysis. PLoS One 2012,7,e46272.

doi:10.1371/journal.pone.0046272. [ https://www.ncbi.nlm.nih.gov/pmc/articles/PMC6599292/][ https://www.ncbi .nlm.nih.gov/pubmed/23029458] 
15. Castle, P. E.; Hillier, S. L.; Rabe, L. K.; Hildesheim, A.; Herrero, R.; Bratti, M. C.; Alfaro, M. An association of cervical inflammation with high-grade cervical neoplasia in women infected with oncogenic human papillomavirus (HPV). Cancer Epidemiology Biomarkers \& Prevention 2001, 10, 1021-1027.

[https://cebp.aacrjournals.org/content/10/10/1021.long][https://www.ncbi.nlm.nih.gov/pubmed/?term=An+associat ion+of+cervical+inflammation+with+high-grade+cervical+neoplasia+in+women+infected+with+oncogenic+huma $\mathrm{n}+$ papillomavirus+(HPV)]

16. Zhao, R; Zhang, W.Y.; Wu, M.H.; Zhang, S.W.; Pan, J; Zhu, L; Zhang, Y.P.; Li, H; Gu, Y.S.; Liu, X.Z. Human papillomavirus infection in Beijing, People's Republic of China: a population-based study. British journal of cancer 2009, 101, 1635-1640

[https://www.ncbi.nlm.nih.gov/pmc/articles/PMC2778508/][https://www.ncbi.nlm.nih.gov/pubmed/?term=British +journal+of+cancer+2009+Human+papillomavirus+infection+in+Beijing $\% 2 \mathrm{C}+$ People $\% 27 \mathrm{~s}+$ Republic+of+China $\% 3 \mathrm{~A}+\mathrm{a}+$ population-based+study]

17. Meerding, .W.;van Ballegooijen, M; Burger, M.P.M.; Van D.A.; Marle, M.E.; Quint, W.G.V.; Habbema, J.D.F. Human papillomavirus testing for triage of women referred because of abnormal smears. a decision analysis considering outcomes and costs. Journal of clinical epidemiology 2002,55, 1025-1032

[https://www.jclinepi.com/article/S0895-4356(02)00456-0/fulltext][https://www.ncbi.nlm.nih.gov/pubmed/?term= Human+papillomavirus+testing+for+triage+of+women+referred+because+of+abnormal+smears.+a+decision+anal ysis+considering+outcomes+and+costs]

18. Herrero, R; Ferreccio, C; Salmeron, J; Almonte, M; Sanchez, G.I.; Lazcano-Ponce, E; Jeronimo, J. New approaches to cervical cancer screening in Latin America and the Caribbean. Vaccine 2008, 26 Suppl 11,L49-58. doi:10.1016/j.vaccine.2008.05.025

[https://www.sciencedirect.com/science/article/pii/S0264410X08005987?via\%3Dihub][https://www.ncbi.nlm.nih. gov/pubmed/?term=New+approaches+to+cervical+cancer+screening+in+Latin+America+and+the+Caribbean.+V accine+2008]

19. Bosch, F. X.; Manos, M. M.;Munoz, N.;Sherman, M. E.; Jansen, A.;Peto, J.;Schiffman, M. H.; Moreno, V.;Kurman, R.;Shah, K. V. Prevalence of HPV DNA in cervical cancer: a worldwide perspective. J. Natl. Cancer. Inst. (Bethesda) 1995, 87,796-802.

[https://academic.oup.com/jnci/article-abstract/87/11/796/1141620?redirectedFrom=fulltext][https://www.ncbi.nl m.nih.gov/pubmed/?term=Prevalence + of $+\mathrm{HPV}+\mathrm{DNA}+\mathrm{in}+$ cervical + cancer\% $3 \mathrm{~A}+\mathrm{a}+$ worldwide + perspective.$+\mathrm{J} .+\mathrm{N}$ atl.+Cancer]

20. Walboomers, J.; Jacob, M.;Manos, M.;Bosch, F. X.;Klummer, J. A.;Shah,K. V.; Snijders, P. J.;Peto, J.;Meijer, C. J.; Munoz, N. Human papillomavirus is a necessary cause of invasive cervical cancer worldwide. $J$.

Pathol.1999.198, 12-19.

[https://onlinelibrary.wiley.com/doi/abs/10.1002/\%28SICI\%291096-9896\%28199909\%29189\%3A1\%3C12\%3A

\%3AAID-PATH431\%3E3.0.CO\%3B2-F][https://www.ncbi.nlm.nih.gov/pubmed/10451482]

21. Tewari, K.S.; Monk, B.J. New strategies in advanced cervical cancer: from angiogenesis blockade to immunotherapy. Clin. Cancer Res. 2014, 20, 5349 - 5358. [https://doi.org/10.1158/1078-0432.CCR-14-1099]

22. Ames, B. N.; Gold, L. S.; Willett, W. C. The causes and prevention of cancer. Proc. Natl. Acad. Sci. 1995, 92, $5258-5265$.

[https://www.ncbi.nlm.nih.gov/pmc/articles/PMC41674/][https://www.ncbi.nlm.nih.gov/pubmed/7777494]

23. Fan, Y.Y.; Nan,Y.; Huang,J.J.; Zhong, H.; Zhou, W.D.Up-regulation of inflammation-related LncRNA-IL7R predicts poor clinical outcome in patients with cervical cancer. Biosci Rep. 2018, 38,

BSR20180483.[ https://www.ncbi.nlm.nih.gov/pmc/articles/PMC5997790/][https://www.ncbi.nlm.nih.gov/pubme $\mathrm{d} /$ ?term=Up-regulation+of+inflammation-related+LncRNA-IL7R+predicts+poor+clinical+outcome+in+patients+ with+cervical+cancer]

24. Wudtisan, J.; Tantipalakorn, C.; Charoenkwan, K.; Sreshthaputra, R.A.; Srisomboon, J.Factors Associated with Development of High-Grade Squamous Intraepithelial Lesions of the Uterine Cervix in Women Younger than 30 Years. Asian Pac J Cancer Prev. 2019,20,1031-1036.

[http://journal.waocp.org/?sid=Entrez:PubMed\&id=pmid:31030470\&key=2019.20.4.1031][https://www.ncbi.nlm. nih.gov/pubmed/31030470]

25. Amrei, K.;Priscilla, D.;Aleksandra, Pesic.;Saviour, Tetteh.;Benjamin, H.;Isaac, Gedzah.;Comfort, M. W.;Joseph, E. A.;Anna-Lisa, B.;Daniela, H.;Michael, P.;Andreas M. K. Characterization of Human Papillomavirus prevalence and risk factors to guide cervical cancer screening in the North Tongu District, Ghana. PLoS One 2019 ,14,e0218762. doi: 10.1371/journal.pone.0218762. eCollection 2019.

[https://journals.plos.org/plosone/article?id=10.1371/journal.pone.0218762][https://www.ncbi.nlm.nih.gov/pubme $\mathrm{d} /$ ?term=Characterization+of + Human+Papillomavirus+prevalence+and+risk+factors+to+guide+cervical+cancer+s creening+in+the+North+Tongu+District\%2C+Ghana]

26. Vinodhini, K.; Shanmughapriya, S.; Das, B.C.; Natarajaseenivasan, K. Prevalence and risk factors of HPVinfection among women from various provinces of the world. Arch Gynecol Obstet. 2012, 285,771 - 7. 
https://doi.org/10.1007/s00404-011-2155-8 PMID: 22159694.

[https://link.springer.com/article/10.1007\%2Fs00404-011-2155-8][ https://www.ncbi.nlm.nih.gov/pubmed/?term= Prevalence+and+risk+factors+of+HPVinfection+among+women+from+various+provinces+of+the+world.] 27. Okunade, K.S.; Nwogu, C.M.; Oluwole, A.A.; Anorlu, R.I. Prevalence and risk factors for genital high-risk human papillomavirus infection among women attending the out-patient clinics of a university teaching hospital in Lagos, Nigeria. Pan Afr Med J. 2017, 28,227. https://doi.org/10.11604/pamj.2017.28.227.13979 PMID: 29629013 [https://www.ncbi.nlm.nih.gov/pmc/articles/PMC5882206/][https://www.ncbi.nlm.nih.gov/pubmed/?term=Prevale nce+and+risk+factors+for+genital+high-risk+human+papillomavirus+infection+among+women+attending+the+o ut-patient+clinics+of+a+university+teaching+hospital+in+Lagos]

28. Kasamatsu, E.; Rodríguez Riveros M.I.; Soilan, A.M.; Ortega, M.; Mongelós, P.; Páez, M.; Castro, A.; Cristaldo, C.; Báez, F.R.; Centurión, C.C.; Vester, J.; Barrios, H.; Villalba, G.; Amarilla, M.L.; Giménez, G.; Caubere, E.; Hernández, M.L.; Baena, A.; Almonte, M.; Herrero, R.; Mendoza, L.P.; ESTAMPA Paraguay Center study group. Factors associated with high-risk human papillomavirus infection and high-grade cervical neoplasia: A population-based study in Paraguay. PLoS One 2019, 14, e0218016. doi:

10.1371/journal.pone.0218016. eCollection2019.

[ https://www.ncbi.nlm.nih.gov/pmc/articles/PMC6597051/][ https://www.ncbi.nlm.nih.gov/pubmed/?term=Facto rs+associated+with+high-risk+human+papillomavirus+infection+and+high-grade+cervical+neoplasia\%3A+A+po pulation-based+study+in+Paraguay.]

29. Liu, Z.C.; Liu, W.D.; Liu, Y.H.; Ye, X.H.; Chen, S.D. .Multiple Sexual Partners as a Potential Independent Risk Factor for Cervical Cancer: a Meta-analysis of Epidemiological Studies. Asian Pac

$J$ Cancer Prev. 2015,16,3893-900.[http://journal.waocp.org/?sid=Entrez:PubMed\&id=pmid:25987056\&key=2015. 16.9.3893][ https://www.ncbi.nlm.nih.gov/pubmed/?term=Multiple+Sexual+Partners+as+a+Potential+Independent +Risk+Factor+for+Cervical+Cancer\%3A+a+Meta-analysis+of+Epidemiological+Studies.]

30. Sales, K.J.; Katz, A.A .Inflammatory pathways in cervical cancer - the UCT contribution. S Afr Med J. 2012, 102, 493-6. [https://www.ncbi.nlm.nih.gov/pubmed/22668947]

31. Heher, Y.K.; Chen, Y.G.; VanderLaan, P.A. Measuring and assuring quality performance in cytology: A toolkit. Cancer Cytopathol. 2017,125,502-507. doi:

10.1002/cncy.21831.[https://onlinelibrary.wiley.com/doi/full/10.1002/cncy.21831][https://www.ncbi.nlm.nih.gov/ pubmed/28609007]

32. Liu, Y.; Zhang, L.; Zhao, G.; Che, L.; Zhang, H.; Fang, J.The clinical research of Thinprep Cytology Test (TCT) combined with HPV-DNA detection in screening cervical cancer. Cell Mol Biol (Noisy-le-grand). 2017, 63, 92-95.doi:10.14715/cmb/2017.63.2.14.[https://www.ncbi.nlm.nih.gov/pubmed/?term=The+clinical+research+of+ Thinprep+Cytology+Test+(TCT)+combined+with+HPV-DNA+detection+in+screening+cervical+cancer.] 33. You, W.; Li, S.; Du, R.; Zheng, J.; Shen, A. Epidemiological study of high-risk human papillomavirus infection in subjects with abnormal cytological findings in cervical cancer screening.Exp Ther Med.

2018,15,412-418. doi: 10.3892/etm.2017.5357. Epub 2017 Oct

[https://www.ncbi.nlm.nih.gov/pmc/articles/PMC5763653/][https://www.ncbi.nlm.nih.gov/pubmed/29375696] 34. Ma, L.; Lei, J.; Ma, L.;Cong, X.; Wang ,N.; Yang ,H.; Liu, Q.; Yu, Y.; Cao, Y. Characteristics of women infected with human papillomavirus in a tertiary hospital in Beijing China, 2014-2018. BMC Infect Dis. 2019, 19,670.doi:10.1186/s12879-019-4313-8.[https://www.ncbi.nlm.nih.gov/pmc/articles/PMC6664751/][https://www. ncbi.nlm.nih.gov/pubmed/?term=Characteristics+of+women+infected+with+human+papillomavirus+in+a+tertiary +hospital+in+Beijing+China\%2C+2014\%E2\%80\%932018]

35. Wang, Y.; Yu, Y.H.; Shen, K.; Xiao, L.; Luan, F.; Mi, X.J.; Zhang, X.M.; Fu, L.H.; Chen, A.; Huang, X. Cervical Cancer Screening and Analysis of Potential Risk Factors in 43,567 Women in Zhongshan, China.Asian Pac J Cancer Prev. 2014,15,671-6.

[http://journal.waocp.org/?sid=Entrez:PubMed\&id=pmid:24568476\&key=2014.15.2.671][https://www.ncbi.nlm.ni h.gov/pubmed/?term=Cervical+Cancer+Screening+and+Analysis+of+Potential+Risk+Factors+in+43\%2C $567+$ Wo men+in+Zhongshan]

36. Rousset-Jablonski, C,.;Reynaud, Q.; Nove-Josserand, R.; Ray-Coquard, I.; Mekki, Y.; Golfier, F.; Durieu, I.Study conducted in Lyon France. High proportion of abnormal pap smear tests and cervical dysplasia in women with cystic fibrosis. Eur J Obstet Gynecol Reprod Biol. 2018,221,40-45. doi: 10.1016/j.ejogrb.2017.12.005. Epub 2017 Dec 9.

[https://www.ejog.org/article/S0301-2115(17)30544-4/fulltext][ https://www.ncbi.nlm.nih.gov/pubmed/?term=Hig $\mathrm{h}+$ proportion+of+abnormal+pap+smear+tests+and+cervical+dysplasia+in+women+with+cystic+fibrosis] 37. Dharaiya, N.;Maitra, N.Correlation of Cytology and Colposcopic Findings Using Reid's Index in VIA-Positive Women. J Obstet Gynaecol India. 2014,64, 284-8. doi: 10.1007/s13224-014-0513-8. Epub 2014 Apr 12.[https://www.ncbi.nlm.nih.gov/pmc/articles/PMC4126948/][https://www.ncbi.nlm.nih.gov/pubmed/?term=Corr elation+of+Cytology+and+Colposcopic+Findings+Using+Reid\%27s+Index+in+VIA-Positive+Women] 38. Zhao,J,; Zhang,X.G.; Ma,J.; Liu,G.W.; Yao,D.X.; Zhang,W.Y.; Wang,J.D.; Wei,L.H.; Zhao,Y.; Zeng, Y. Clinical performance characteristics of the Cervista HPV HR test kit in cervical cancer screening in China.J Low Genit Tract Dis. 2012, 16, 358- 
363. doi: 10.1097/LGT.0b013e31824b9bf9.[https://www.ncbi.nlm.nih.gov/pubmed/?term=Clinical+performance+ characteristics+of+the+Cervista+HPV+HR+test+kit+in+cervical+cancer+screening+in+China]

39. Rana, S.; Hoda, K.L.; Fadi, W.; Abdul, K.D. Gynecologic cytology on conventional and liquid-based preparations: a comprehensive review of similarities and differences. Cytopathol. 2013, 41,257-278. Published online 2012 Apr 17. doi: $10.1002 /$ dc. 22842

[https://onlinelibrary.wiley.com/doi/abs/10.1002/dc.22842][https://www.ncbi.nlm.nih.gov/pubmed/?term=Gynecol ogic+cytology+on+conventional+and+liquid-based+preparations $\% 3 \mathrm{~A}+\mathrm{a}+$ comprehensive+review+of+similarities+ and+differences]

40. Zappacosta, R.; Sablone, F.; Pansa, L.; Buca, D.; Buca, D.; Rosini, S. Analytic and Diagnostic Performances of Human Papillomavirus E6/E7 mRNA Test on up-to 11-Year-Old Liquid-Based Cervical Samples. A

Biobank-Based Longitudinal Study. Int J Mol Sci. 2017,18,1480. Published 2017 Jul 11.

doi:10.3390/ijms18071480

[https://www.ncbi.nlm.nih.gov/pmc/articles/PMC5535970/][https://www.ncbi.nlm.nih.gov/pubmed/?term=Analyti c+and+Diagnostic+Performances+of+Human+Papillomavirus+E6\%2FE7+mRNA+Test+on+up-to+11-Year-Old+ Liquid-Based+Cervical+Samples]

41. Schwebke, J. R.; Schulien, M. B.; Zajackowski, M. Pilot study to evaluate the appropriate management of patients with coexistent bacterial vaginosis and cervicitis. Infectious Diseases in Obstetrics and Gynecology 1995 $3,119-122$.

[https://www.ncbi.nlm.nih.gov/pmc/articles/PMC2364425/][https://www.ncbi.nlm.nih.gov/pubmed/?term=Pilot+st $\mathrm{udy}+$ to+evaluate+the+appropriate+management+of+patients+with+coexistent+bacterial+vaginosis+and+cervicitis ]

42. Madaan, N.; Pandhi, D.; Sharma, V.; Bhattacharya, S.N.; Guleria, K.; Mishra, K.; Bharadwaj, M. Association of abnormal cervical cytology with coinfection of human papillomavirus and Chlamydia trachomatis.Indian J Sex Transm Dis AIDS. 2019, 40, 57-63. doi: 10.4103/ijstd.IJSTD_9_19.

[https://www.ncbi.nlm.nih.gov/pmc/articles/PMC6532497/][Indian J Sex Transm Dis AIDS. 2019

Jan-Jun;40(1):57-63. doi: 10.4103/ijstd.IJSTD_9_19.]

43. Greenberg, M. D.; Reid, R.; Schiffman, M.; Campion, M. J.; Precop, S. L.;Berman, N. R.;Zemlo, T.;Husain, M.; Herman, G.; Omatoa, K. H.; Lorincz,A. T. A prospective study of biopsy-confirmed cervical intraepithelial neoplasiagrade 1: colposcopic, cytological, virological risk factors for progression. J.Lower Genit. Tract Dis.1999, 3,104-110. [https://www.ncbi.nlm.nih.gov/pubmed/25950556]

44. Castle, P.E.; Giuliano, A.R. Chapter 4: genital tract infections, cervical inflammation, and antioxidant nutrients-assessing their roles as human papillomavirus cofactors. J Natl Cancer Inst Monogr 2003,31,29-34. [https://academic.oup.com/jncimono/article/2003/31/29/951057][ https://www.ncbi.nlm.nih.gov/pubmed/?term=g enital+tract+infections $\% 2 \mathrm{C}+$ cervical+inflammation $\% 2 \mathrm{C}+\mathrm{and}+$ antioxidant+nutrients $\% \mathrm{E} 2 \% 80 \% 93$ assessing+their +roles+as+human+papillomavirus+cofactors]

45. Kirvis T.P.; Margarita B.R.; Claudia M.G.; Ana I B.G.; Víctor, H. B.M.; Oscar P.Z.; Vicente, M.M. Role of IL-10 and TGF- $\beta 1$ in local immunosuppression in HPV-associated cervical neoplasia .World J Clin

Oncol. 2014, 5,753-763. Published online 2014 Oct 10. doi: 10.5306/wjco.v5.i4.753

[https://www.ncbi.nlm.nih.gov/pmc/articles/PMC4129538/[https://www.ncbi.nlm.nih.gov/pubmed/?term=Role+o f+IL-10+and+TGF-\%CE\%B21+in+local+immunosuppression+in+HPV-associated+cervical+neoplasia]

46. L. Feller, N. H. Wood, R. A. G. Khammissa, U. M. E. Chikte, R. Meyerov, J. Lemmer SADJ. HPV modulation of host immune responses. 2010, 65,266-268. [https://www.ncbi.nlm.nih.gov/pubmed/20879650]

47. Lv X.J.; Tang, Q.; Tu, Y.Q.; Yan, D.D.; Wei, Q.C. Long noncoding RNA PCAT6 regulates cell growth and metastasis via Wnt/B-catenin pathway and is a prognosis marker in cervical cancer. Eur Rev Med Pharmacol Sci. 2019, 23,1947-1956. doi:10.26355/eurrev_201903_17233

[https://www.europeanreview.org/article/17233][https://www.ncbi.nlm.nih.gov/pubmed/?term=Long+noncoding+ RNA+PCAT6+regulates+cell+growth+and+metastasis+via\%C2\%A0Wnt\%2F\%CE\%B2-catenin\%C2\%A0pathwa $\mathrm{y} \% \mathrm{C} 2 \% \mathrm{~A} 0 \mathrm{and}+\mathrm{is}+\mathrm{a}+$ prognosis+marker+in $\% \mathrm{C} 2 \% \mathrm{~A} 0$ cervical+cancer]

48. Li, H.; Zhang, W.; Yan, M.; Qiu, J.; Chen, J.; Sun, X.; Chen, X.; Song, L.; Zhang, Y. Nucleolar and spindle associated protein 1 promotes metastasis of cervical carcinoma cells by activating Wnt/ $\beta$-catenin signaling.J Exp Clin Cancer Res. 2019, 38,33. doi: 10.1186/s13046-019-1037-y.

[https://www.ncbi.nlm.nih.gov/pmc/articles/PMC6346521/][https://www.ncbi.nlm.nih.gov/pubmed/?term=Nucleol ar+and+spindle+associated+protein+1+promotes+metastasis+of $\% \mathrm{C} 2 \% \mathrm{~A} 0$ cervical $\% \mathrm{C} 2 \% \mathrm{~A} 0$ carcinoma+cells+by+a ctivating $\% \mathrm{C} 2 \% \mathrm{~A} 0 \mathrm{Wnt} \% 2 \mathrm{~F} \% \mathrm{CE} \% \mathrm{~B} 2$-catenin $\% \mathrm{C} 2 \%$ A0signaling]

49. Zheng, M.; Zhou, Q.; Liu, X.; Wang, C.; Liu, G. CTHRC1 overexpression promotes cervical carcinoma progression by activating the Wnt/PCP signaling pathway.Oncol Rep. 2019, 41, 1531-1538. doi:

10.3892/or.2019.6963. Epub 2019 Jan 10. 
[https://www.ncbi.nlm.nih.gov/pmc/articles/PMC6365690/][https://www.ncbi.nlm.nih.gov/pubmed/?term=CTHR $\mathrm{C} 1+$ overexpression+promotes $\% \mathrm{C} 2 \% \mathrm{~A} 0$ cervical $\% \mathrm{C} 2 \% \mathrm{~A} 0$ carcinoma+progression+by+activating+the $\% \mathrm{C} 2 \% \mathrm{~A} 0 \mathrm{Wn}$ t\%2FPCP $\% \mathrm{C} 2 \% \mathrm{~A} 0$ signaling $\% \mathrm{C} 2 \% \mathrm{~A} 0$ pathway]

50. Torres-Poveda K1,2, Bahena-Román M3, Delgado-Romero K4, Madrid-Marina V3. A prospective cohort study to evaluate immunosuppressive cytokines as predictors of viral persistence and progression to pre-malignant lesion in the cervix in women infected with HR-HPV: study protocol.BMC Infect Dis. 2018 ,18, 582. doi: 10.1186/s12879-018-3490-1.

[https://www.ncbi.nlm.nih.gov/pmc/articles/PMC6245844/][https://www.ncbi.nlm.nih.gov/pubmed/?term=A+pros pective+cohort+study+to+evaluate+immunosuppressive+cytokines+as+predictors+of $\% \mathrm{C} 2 \% \mathrm{~A} 0 \mathrm{viral} \% \mathrm{C} 2 \% \mathrm{~A} 0$ pers istence+and+progression+to+pre-malignant+lesion+in+the+cervix+in+women+infected+with+HR-HPV]

51. Ishita, G.; Richard, M.; Srabani, M.; Dipanwita, B.; Pratip,K.; Ranajit, M.; Jaydip, B.; Partha,B. Association between high risk human papillomavirus infection and co-infection with Candida spp. and Trichomonas vaginalis in women with cervical premalignant and malignant lesions. J ClinVirol. 2016, 87, 43-48. Published online 2016 Dec 12. doi: 10.1016/j.jcv.2016.12.007

[https://www.ncbi.nlm.nih.gov/pmc/articles/PMC5720658/][https://www.ncbi.nlm.nih.gov/pubmed/?term=Signific ance + of + Compression+in+Binucleation + while+Differentiating+Reactive+Cellular+Changes + Between $+H u m a n+P$ apillomavirus+and+Candida+Infections]

52. Amorim, A.T.; Marques, L.M.; Campos, G.B.; Lobão, T.N.; de Souza Lino, V.; Cintra, R.C.; Andreoli, M.A.; Villa, L.L.; Boccardo, E.; Junior, A.C.R.B.; López, R.V.M.; Dos Santos, D.B.; de Souza, G.M.; Romano, C.C.; Timenetsky, J. Co-infection of sexually transmitted pathogens and Human Papillomavirus in cervical samples of women of Brazil. BMC Infect Dis. 2017,17, 769. doi: 10.1186/s12879-017-2835-5. [https://www.europeanreview.org/article/17233][https://www.ncbi.nlm.nih.gov/pubmed/?term=Long+noncoding+ RNA+PCAT6+regulates+cell+growth+and+metastasis+via\%C2\%A0Wnt\%2F\%CE\%B2-catenin \%C2\%A0pathwa $\mathrm{y} \% \mathrm{C} 2 \% \mathrm{~A} 0$ and $+\mathrm{is}+\mathrm{a}+$ prognosis+marker+in $\% \mathrm{C} 2 \% \mathrm{~A} 0$ cervical+cancer]

53. Schwartz, R. S.; Eltzschig, H. K.; Carmeliet, P. Hypoxia and inflammation. New England Journal of Medicine 2011,364,656-665.[https://www.ncbi.nlm.nih.gov/pmc/articles/PMC3930928/][https://www.ncbi.nlm.nih.gov/pub $\mathrm{med} / 21323543]$

54. Coussens, L. M.; Werb, Z. Inflammation and cancer. Nature, 2002,420, 860-867.

[https://www.ncbi.nlm.nih.gov/pmc/articles/PMC2803035/][https://www.ncbi.nlm.nih.gov/pmc/articles/PMC2803 035/]

55. Rook, G.A.; Dalgleish, A.Infection, immunoregulation, and cancer. Immunol Rev. 2011, 240,141-59. doi:10.1111/j.1600-065X.2010.00987.x.[https://onlinelibrary.wiley.com/doi/abs/10.1111/j.1600-065X.2010.00987 .x?sid=nlm\%3Apubmed][https://www.ncbi.nlm.nih.gov/pubmed/?term=Dalgleish\%2C+A.+G.\%3B+Inflammation +and+Cancer]

56. Li, B.; Zhang, L.; Zhao, J.; Tan, G.; Zhang, W.; Zhang, N.; Tian, J.; Qu, P.The value of cytokine levels in triage and risk prediction for women with persistent high-risk human papilloma virus infection of the cervix.Infect Agent Cancer. 2019, 28,14:16. doi: 10.1186/s13027-019-0231-z. eCollection

[https://www.ncbi.nlm.nih.gov/pmc/articles/PMC6599292/][https://www.ncbi.nlm.nih.gov/pubmed/?term=The+va lue+of+cytokine+levels+in+triage+and+risk+prediction+for+women+with+persistent+high-risk+human+papillom a+virus+infection+of+the+cervix]2019.[https://www.ncbi.nlm.nih.gov/pmc/articles/PMC6599292/pdf/13027_201 9_Article_231.pdf][https://www.ncbi.nlm.nih.gov/pubmed/?term=The+value+of+cytokine+levels+in+triage+and+ risk+prediction+for+women+with+persistent+high-risk+human+papilloma+virus+infection+of+the+cervix] 